\title{
Habitat Preference and Nest Predation Risk in the Blackbird (Turdus merula)
}

\author{
Kim, Miran \\ Applied Ecology and Conservation Biology, University of East Anglia, Norwich, NR4 7TJ, UK
}

\begin{abstract}
For last 150 years, blackbirds have moved from their ancestral habitat, the woodland edge, to man-made habitats such as farmland, parks and gardens. These alternative habitats have become one of main blackbird habitats. I compared density of nests and blackbirds in parks, woodland and campus of University of East Anglia to investigate habitat preference. Blackbirds preferred the area covered by $10 \sim 50 \%$ of tree or bush patches for their foraging and nesting sites. Blackbirds were more frequently found near buildings rather than far from buildings. Nest characteristics did not affect predation rate and nest preference. This study suggests that man-made habitats may be important for avoiding predation.
\end{abstract}

Key words: Blackbirds, Habitat preference, Nest characteristics, Patch cover, Predation

\section{INTRODUCTION}

The blackbird (Tundra merula) is one of the commonest species is Britain. There are more than 4,400,000 breeding pairs in Britan (British Garden Birds 2003). Although blackbird population has declined after the cold winter of 1962/1963, the population has quickly recovered. However, the population declined from the mid-1970s. The common Bird Census (CBC) showed that the blackbird population declined by 33\% from 1972 to 1996 in Britain (Siriwardena et al. 1998). The cause of this decline was still unclear although Fuller et al. (1995) suggested that agricultural intensification is likely to have contributed to this decline. The recent survey of the $\mathrm{CBC}$ showed that the declined of blackbird population might have ceased (Marchant et al. 1990). However, the blackbird population has not recovered yet.

The ancestral habitat of blackbirds is the woodland edge. Blackbirds have moved from the woodland to man-made habitats, such as farmland hedgerows, parks, moorland edge, suburban garden and even urban area over the last 150 200 years (Sharrock 1976). Local habitat management requires the details of habitat use and knowledge of the population dynamics of the birds (Stowe et al. 1993, Evans and Smith 1994, Green 1996). Habitat preference that determines reproductive success has often been studied to recover declining population (e.g. Chamberlain et al. 1999).

Nest predation is one of the important factors to affect reproductive success. In many birds, the main cause of nest failure is predation (Ricklefs 1969, Filliater et al. 1994, Hatchwell et al. 1996). Martin (1993) showed that nest predation was responsible for $80 \%$ of loss for open-cup nesters like blackbirds. Predation rate on nests often related to habitat characteristics. Nest characteristics, such as nest height, concealment, accessibility to nests (Fillater et al. 1994) and patch cover around nests (Martin 1998) can affect predation risk. Human activity may influence predation risk because it may change the behaviour of parents or predators (Gill et al. 1996). Several previous studies suggest that human activity can increase predation rate due to the frequent absence of parents (Jokimaki and Huhta 2000, De Santo and Willson 2001) whilst other studies suggest that human activity can reduce predation rate due to the low predator density in the presence of human (Liley 1999).

The aims of this study were to investigate which habitats and nest characteristics are preferred by blackbirds in feeding and nesting site and how predation risks affect their habitat selection.

\section{STUDY AREA AND METHODS}

This study was carried on University of East Anglia campus (UEA), woodland and Earlham Park, Norwich, UK from April to June, 2003 (Fig. 1). The study area included parkland (52 ha), building area (58 ha) and mixed woodland (36 ha).

\section{Habitat Preference}

The observed blackbirds in study area were recorded on the map in scale of 1:2,500 every week from 06.00 to 09.00 (GMT) excluding raining days. Because human activity differed between weekdays and weekends in study area, a half of mapping was carried out during weekdays and the rest half was carried out during weekends. Density of blackbirds and their nests was estimated as the

\footnotetext{
* Corresponding author; Phone: +82-10-3161-1528, e-mail: miran318@hotmail.com
} 


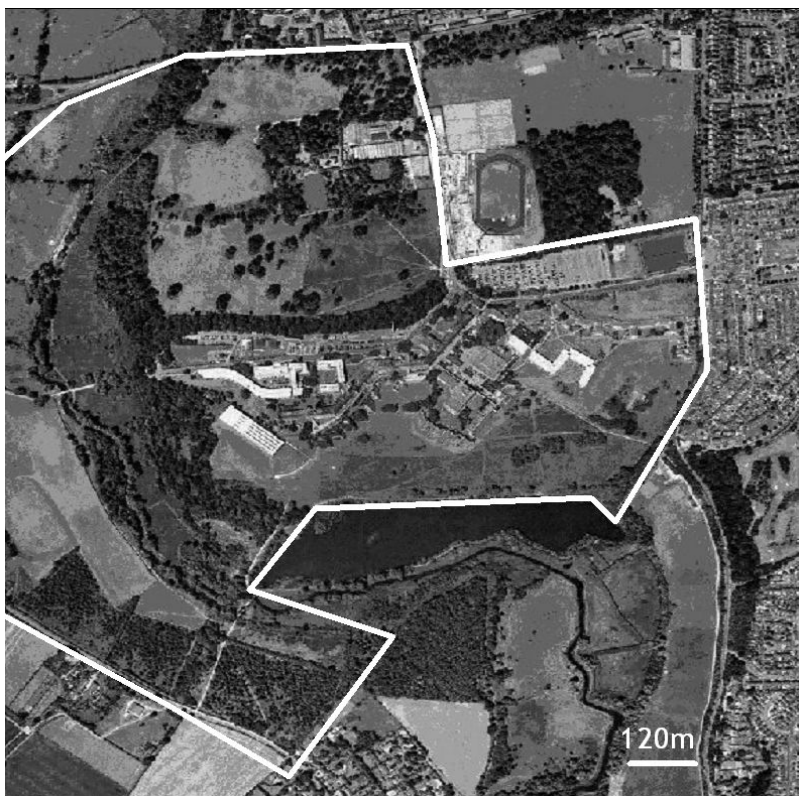

Fig. 1. Study area in woodland, Earlham park and University of East Anglia (UEA)

number of birds or nests per ha. After breeding was completed, I revisited all nests that had been monitored and recorded the nest characteristics. Habitat characteristics were recorded in (1) vegetation types (bush or tree) where nests were built and (2) habitat types (woodland, grassland or near buildings) where nests were built and (3) patch cover (\%). Patch cover was estimated using a map. First, I overlapped the film with small square grids on the map each ha and counted the number of patch cover grids and multiplied the number of square grids to the real size $\left(25 \mathrm{~m}^{2}\right)$ of the square in the map scale. Nest characteristics were recorded as (1) nest height from the ground to the tope of nest, (2) maximum horizontal distance from a nest to the edge of a bush and (3) concealment of nests. Concealment of nests was categorized to 4 classes: $0 \sim 10 \%$ (Score 1), 11 40\% (Score 2), $41 \sim 80 \%$ (Score 3) and $81 \sim 100 \%$ (Score 4).To measure the human disturbance, I recorded the number of people whom I met during the mapping. The human activity was categorized in 3 categories according to the number of people: score 1 was area with intensive human activities (more than 10 people per ha); score 2 was area with intermediated human activities (between 1 9 people per ha); score 3 was area with low human activities (less than one people per ha). Predators of blackbirds were reported as grey squirrels (Sciurus caroliniensis), magpies (Pica pica), carrion crows (Crovus cornix), jays (Garrulus glandarious) and jackdaws (Corvus monedula) (Møller 1987). Domestic cats and birds of prey were also recorded as predators of adults and juveniles. At visiting nests, I recorded the number of these potential predators on the map and estimated density of potential predators to investigate predation risks.

\section{Egg Predation Experiment}

The egg predation was monitored using 172 plasticine eggs in 43 used nests from $12^{\text {th }}$ to $27^{\text {th }}$ June, 2003. Artificial eggs often used for investigating predation risks (e.g. Cresswell 1997, Møller 1998, Taylor 2002). Plasticine eggs imitated real blackbird eggs in size (approx. $29 \times 22 \mathrm{~mm}$ ), colour (greenish blue) and spots (dark brown spots) except weight (palsticine eggs: approx. $12 \mathrm{~g}$; blackbird eggs: approx. $8 \mathrm{~g}$ ) as much as I could. In experimental nests, 4 plasticine eggs which were same clutch size as a modal clutch were placed in each used nest. To reduce the odor of artificial egg, eggs were kept in a bird-bag with avian feathers. One of 4 eggs was tied to the branch near experimental nests to prevent predators taking all eggs out of nests. 43 experiment nests were monitored from 16.00 to 19.00 (GMT) every 3 days for 15 days including three raining days. I checked nests whether eggs were depredated in experimental nests and natural nests. A visit of nests was less than 5 seconds. If eggs were destroyed or missed, the nest was considered as predated.

\section{Analysis}

Jacobs' Index (Jacobs 1974) was used to estimate habitat preference:

$$
D=(r-p) /(r+p-2 r p)
$$

where $r$ is the proportion of birds or nests recorded in a particular habitat types and $p$ is the proportion of the habitat types. $D$ has a range from +1 to $-1(D<0$ : avoided ; $D>0$ : preferred habitat). SPSS 11.0 was used for analysing data. Yates' correction in Chisquare tests was used for comparing only two categories (Fowler and Cohen 1995). Mann-Whitney tests were used for data which were not normally distributed.

\section{RESULTS}

Jacobs' Index showed that blackbirds were frequently observed in sites with $0 \sim 50 \%$ vegetation cover for foraging (Jacobs' Index: 0.223 ) and for nesting (Jacobs' Index: 0.620) (Fig. 2). Grassland and woodland were less preferred by blackbirds for foraging (Jacobs' Index: -0.448) and nesting site (Jacobs's Index: -0.670). Blackbirds frequently used sites with intensive human activity for foraging (Jacobs' Index: 0.630) and for nesting (Jacobs' Index: 0.630). More blackbirds (Jacobs' Index: 0.385) and their nests (Jacobs' Index: 0.635) were found area with intensive human activities than area with less human activities. Mean 110, 13 and 15 people were in UEA campus, Earlharm Park and Woodland per survey, respec- 
tively. They preferred sites with low density of potential predators (Jacobs' Index: 0.620) than sites with high density of potential predators (Jacobs' Index: -0.619 ) for nesting.

Reproductive success was $40.9 \%$ in 26 nests. The main cause of nest failure was egg predation $(66.7 \%)$. Only one nest $(8.4 \%)$ depredated during the chick rearing period. 3 nests were deserted during the incubation period. In experimental nests, 22 nests $(55 \%)$ out of 43 nests were predated for 15 days. Overall egg predation rate did not differ between experimental nests and natural nests $\left(\chi^{2}=0.45\right.$, N.S.).

Nest characterises such as nest height, horizontal distance from the bush or tree edge, nest concealment, did not related to predation rate in 43 experimental nests (Table 1). In experimental nests to identify egg predation risks, egg predation rate significantly higher in nests which were placed in bush than in nests which were placed in trees (Fig. 3). Predation rate of experimental nests did not differ between nests in tree and in bush for the first week, but it was

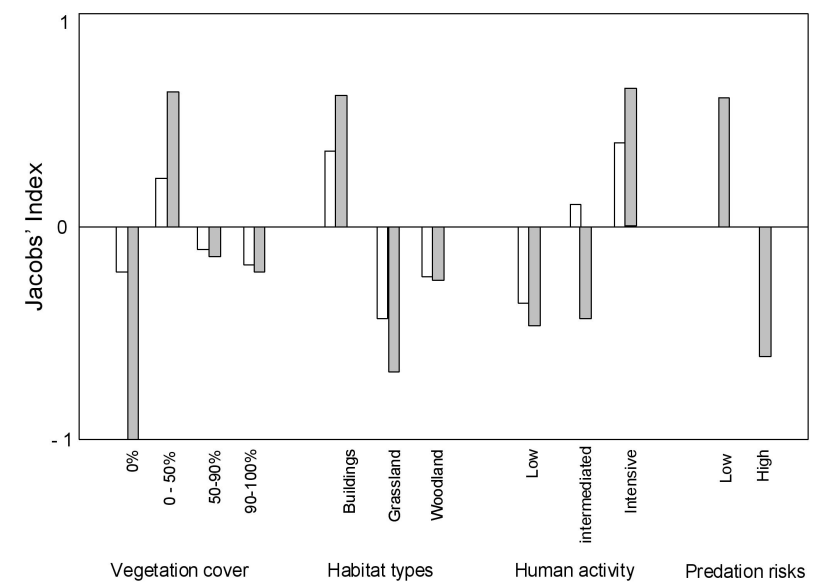

Fig. 2. Jacobs' Index presents preferred habitats according to vegetation cover, habitat types, human activity and predation risks in blackbirds. Empty bars present the sites used by adult birds for foraging and filled bars present the sites used for nesting. Predation risks were categorized in two groups (low and high) using the mean number of predators in habitats. higher in tree nests than bush nests after the second week. More nests were found in sites with buildings than without buildings. Sites with buildings had lower density of potential predators and lower egg predation rate (Table 2).

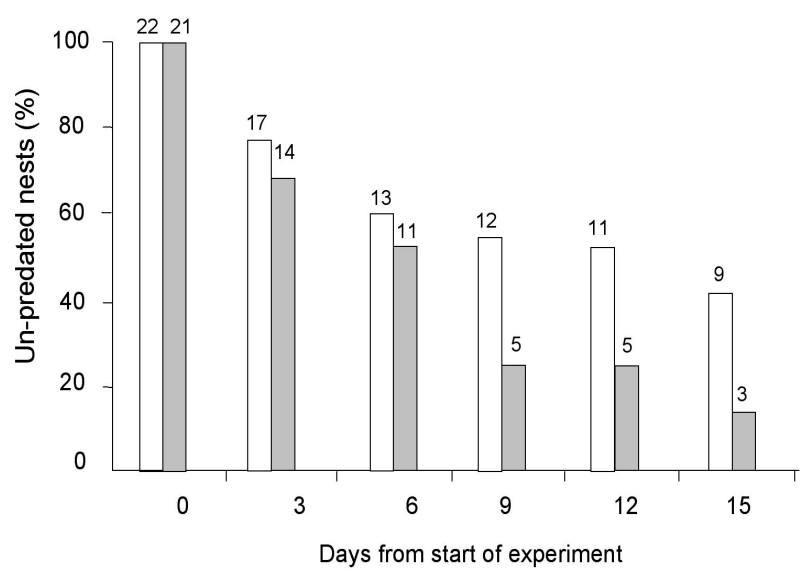

Fig. 3. Un-predated rate (\%) of 43 experimental nests with artificial eggs since experiment was started (days). Empty bars present experimental nests which were placed in bush and filled bars present experimental nests which were placed in tree. The number above bars presents sample size.

Table 2. Comparisons of the density of potential predators, egg predation rate and number of 23 nests between areas without and with buildings. 3 nests of 26 nests were excluded due to missing data

\begin{tabular}{lccc}
\hline \hline & No building & Building & $p$ \\
\hline $\begin{array}{c}\text { Density of potential } \\
\text { predators per ha }\end{array}$ & $0.34 \pm 0.049$ & $0.22 \pm 0.047$ & $0.055^{\mathrm{a}}$ \\
Egg predation rate (\%) & 50 & 21 & $<0.01^{\mathrm{b}}$ \\
No. of nests & 4 & 19 & $<0.01^{\mathrm{b}}$ \\
Mean of people & 110 & 14 & \\
\hline
\end{tabular}

${ }^{a}$ Mann-Whitney U-test, ${ }^{\mathrm{b}}$ Chi-square test (Yates' correction).

Table 1. Nest characteristics of predated and non-predated nests in 43 experimental nests. Sample size is varied due to missing data. Nest concealment was categorized to 4 categories: Score 1: 0 10\%; Score 2: $11 \sim 40 \%$; Score 3: $41 \sim 80 \%$; Score 4: $81 \sim 100 \%$

\begin{tabular}{|c|c|c|c|c|}
\hline & \multicolumn{2}{|c|}{ Mean \pm SE } & \multicolumn{2}{|c|}{$t$-test } \\
\hline & Predated & Non-predated & $t$ & $p$ \\
\hline Nest height (cm) & $134.5 \pm 9.35$ & $131.04 \pm 7.35$ & $t_{42}=0.29$ & 0.77 \\
\hline Horizontal distance from the bush or tree edge & $79.7 \pm 7.05$ & $80.75 \pm 12.50$ & $t_{36}=0.07$ & 0.94 \\
\hline Nest concealment & $2.4 \pm 0.44$ & $2.16 \pm 0.34$ & $t_{37}=0.08$ & 0.93 \\
\hline
\end{tabular}




\section{DISCUSSION}

Blackbirds preferred covered areas up to $50 \%$ for foraging and nesting sites. Totally covered and uncovered sites were not preferred. It may relate to foraging behaviour and diet of blackbirds. Blackbirds eat worms, insects and berries from the ground (Snow 1958, Desrochers 1992). Blackbirds may prefer uncovered area where worms or insects were easily found. However, totally uncovered area may be dangerous to blackbirds because predators also could find blackbirds easier than covered area. I observed that adults and juvenile of blackbirds frequently stayed near bush and hide into bush. Hence, blackbirds may select partially covered area for avoiding predators and finding food.

Interestingly, blackbirds preferred sites with buildings than grassland and woodland although human activity may increase desertion of eggs due to disturbance (Strawiňski 1963). At the UEA campus with intensive human activities (mean 110 people), 3 nests were deserted after laying eggs. It might be due to human disturbance. Although there is human disturbance, more blackbirds nested near buildings. It may be related to lower density of predators near buildings. Sites near buildings had lower density of potential predators.

The other explanation why blackbirds preferred sites near buildings may be easy access to food. I observed several adults and many juveniles often used foods such as bread from the street and garbage bins.

Nest concealment was related to reproductive success (e.g. Hatchwell et al. 1996). Higher concealment of nests may be helpful to avoid nest detection by predators due to low visibility. However, nest concealment in present study of blackbirds was not related to predation rate. Nest height and horizontal distance from the bush edge also did not affect nest predation rate. Osborne \& Osborne (1980) suggested that nest characteristics were not important for the nest site choice near buildings. Advantages of using man-made habitats might greater than disadvantage such as disturbance. In present study, predators might avoid sites with intensive human activities and blackbirds may prefer near buildings for foraging and nesting.

Experimental nests which were placed in trees more predated than nests which were placed in bush a week after experiments started (Fig. 2). Predators may easily access nests which were built in trees comparing to nests which were built in bush. For first 7 days of experiments, predation risk did not differ between nests which were placed in bush and nests which were placed in trees. It might be due to taking a week to be detected by potential predators.

In conclusion, this study suggests that blackbirds preferred partially covered area and man-made habitats. Man-made habitats may be alternative habitats for blackbirds due to low predation risks.

\section{ACKNOWLEDGEMENTS}

I thank my supervisor Professor William Sutherland, advisor Dr Jennifer Gill and Jennifer Ah-king for their comments and helps. Results were a part of MSc thesis in UEA.

\section{LITERATURE CITED}

British garden birds. 2003. http://www.garden-birds.co.uk/blackbird.htm. Chamberlain DE, Wilson AM, Brown SJ, Vickery A. 1999. Effects of type and management on the abundance of skylarks in the breeding season. J Appl Ecol 36: 856-870.

Cresswell W. 1997. Nest predation: the relative effects of nest characteristics, clutch size and parental behaviour. Anim Behav 53: 93103.

De Santo TL, Willson MF. 2001. Predator abundance and predation of artificial nests in natural and anthropogenic coniferous forest edges in SE Alaska. J Field Ornithol 72: 136-149.

Desrochers A. 1992. Age and foraging in European Blackbirds: variation between and within individuals. Anim Behav 43: 885-894.

Evans AD, Smith KW. 1994. Habitat selection of Cirl Buntings Emberiza circlus wintering in Britan. Bird Study 41: 81-87.

Filliater TS, Breitwisch R, Nealen PM. 1994. Predation on Northern Cardinal nests: does choice of nest site matter? Condor 96: 761-768.

Fowler J, Cohen L. 1995. Statistics for Ornithologists. British Trust for Ornithology. UK.

Fuller RJ, Gregory RD, Gibbons DW, Marchant JH, Wilson JD, Baillie SR, Carter N. 1995. Population declines and range contractions among lowland farmland birds in Britain. Conserv Biol 9: 14251441.

Gill JA, Sutherland WJ, Atkinson AR. 1996. A method to quality the effects of human disturbance on animal populations. J Appl Ecol 33: 786-792.

Green RE. 1996. Factors affecting the diet of farmland skylarks Alauda arcensit. J Anim Ecol 47: 913-928.

Hatchwell B, Ghamberlain DE, Perrins CM. 1996. The demography of blackbirds Turdus merula in rural habitats: is farmland a suboptimal habitat? J Appl Ecol 33: 1114-1124.

Jacobs J. 1974. Quantitative measurement of food selection. Oecologia 14: 413-417.

Jokimaki J, Huhta E. 2000. Artificial nest predation and abundance of birds along an urban garden. Condor 102: 838-847.

Liley D. 1999. Predicting the consequence of human disturbance, predation and sea-level raise for ringed plover populations. $\mathrm{PhD}$ Thesis. Univ of East Anglia, Norwich.

Marchant JH, Hudson R, Carter SP, Whittington P. 1990. Population trends in British breeding birds. British Trust for Ornithology, Herts.

Martin TE. 1993. Nest predation among vegetation layers and habitat types: revising the dogmas. Am Nat 141: 897-532.

Martin TE. 1998. Are microhabitat preferences of coexisting species 
under selection and adaptive? Ecology 79: 656-570.

Møller AP. 1987. Egg predation as a selective factor for nest design: an experiment. Oikos 50: 91-94.

Møller AP. 1998. Nest predation and nest site choice in passerine birds in habitat patches of different sizes: a study of magpies and blackbirds. Oikos 53: 215-221.

Osborne P, Osborne L. 1980. The contribution of nest site characteristics to breeding success among blackbirds Turdus merula. Ibis 122: $512-517$.

Ricklefs RE. 1969. An analysis of nesting mortality in birds. Zoology 9: $1-48$.

Sharrock JT. 1976. The Atlas of Breeding Birds in Britan and Ireland. pp 340-341.

Siriwardena GM, Baillie SR, Buckland ST, Fewster RW, Marchant JH, Wilson JD. 1998. Trends in the abundance of farmland birds: quantitative comparison of smoothed common bird census indices. J Appl Ecol 35: 24-43.

Snow DW. 1958. A Study of Blackbirds. British Museum. London. Spear LB, Anderson DW. 1989. Nest site selection by yellow-footed gulls. Condor 91: 91-99.

Stowe TJ, Newton AV, Green RE, Mayes E. 1993. The decline of the corncrake Crex crex in Britan and Ireland in relation to habitat. J Appl Ecol 30: 53-62.

Strwiňski S. 1963. Studies on the synanthropism of birds in the Old Park in Ciechocinek. Acta Ornithol 7: 159-188.

Taylor E. 2002. Predation risk in woodlark Lullula arborea habitat: the influence of recreational disturbance, predator abundance, nest site characteristics and temporal factors. Master Thesis. Univ of East Anglia, Norwich.

(Received February 6, 2009; Accepted February 20, 2009) 